\author{
Matic Pavlič @ http://orcid.org/0000-0001-8248-8860/ \\ University of Ljubljana, Slovenia
}

\title{
Sign Order in Slovenian Sign Language Transitive and Ditransitive Sentences
}

\begin{abstract}
The basic sign order in Slovenian Sign Language (SZJ) is Subject-Verb-Object (SVO). This is shown by analysing non-topicalised or focalised transitive and ditransitive sentences that were elicited from first language SZJ informants using Picture Description Task. The data further reveal that the visual-gestural modality, through which SZJ is transmitted, plays a role in linearization since visually influenced classifier predicates trigger the non-basic SOV sign order in this language.

\section{Keywords}

word/sign order, Slovenian Sign Language, transitives, ditransitives, classifier constructions

Streszczenie

Podstawowy szyk zdania w słoweńskim języku migowym (SZJ) to szyk podmiot-orzeczenie-dopełnienie (SVO). Wskazuje na to analiza zdań bez topikalizacji czy fokalizacji, zawierających czasowniki przechodnie i dwuprzechodnie, wyprodukowanych w trakcie zadania polegającego na opisie obrazów (Picture Description Task) przez informatorów, których pierwszym językiem jest SZJ. Dane pokazują również, że modalność wizualno-gestowa, z której korzysta SZJ, ma wpływ na linearyzację, ponieważ predykaty klasyfikujące oparte na modalności wizualnej wymagają użycia nacechowanego w tym języku szyku SOV.
\end{abstract}

\section{Słowa kluczowe}

szyk zdania/kolejność znaków, słoweński język migowy, czasowniki przechodnie, czasowniki dwuprzechodnie, konstrukcje klasyfikatorów 


\section{Introduction}

\subsection{Word/sign order}

To understand a sentence, it is essential to distinguish the syntactic relations between the constituents involved. One of the mechanisms that relate arguments to the verb is the basic word order. The field of basic word order research opened when Greenberg (1963) discovered that logically possible word orders are not evenly distributed in his sample of thirty languages. He argued convincingly and influentially that, among possible orders, SOV (Subject-Object-Verb; 37\%) and SVO (Subject-Verb-Object; 43\%) are most widely attested in the world's languages, followed by VSO (Verb-Subject-Object; 20\%). On this basis, he generalized that cross-linguistically Subjects mostly precede Objects, that verbs are usually adjacent to Objects and that this pattern further reflects the order of other elements in each language. Linguists have ever since struggled to find out how strong and accurate these tendencies are, how they emerge in human brain, how they are derived and acquired. For example, children acquiring a language predominantly utilize one order, which is considered to be the basic word order. If their language also exhibits other orders, they are subject to the constraints that normally apply to adult speech. This is shown for example by Sugisaki $(2003,2005,2008)$ and references cited there for oral languages, and by Pichler (2001) for sign languages. Although children acquiring a language do not seem to hesitate upon which word order to acquire first, the basic word order is not easily attainable from the speech or sign flow. Linguists try to determine the basic word order of a language with respect to different criteria. Among them, Hawkins (1983: 13) mentions:

- Frequency: the basic word order is the one that is used most often;

- Distribution: the basic word order occurs in the broadest set of syntactic environments;

- Markedness: the basic word order is the one with the least amount of function-indicating phonological, morphological or syntactic marking;

- Pragmatic neutrality: the basic word order is the one that carries no special pragmatic information apart from declarative mood.

According to these criteria, the basic word order is reflected most transparently in the surface order of Subject, Object(s) and Verb in the syntactic environment with the least distributional restrictions, i.e. in a sentence without linguistic or non-linguistic context where the entire event represents new information. The basic word order is thus commonly assumed to be the order of neither topicalised nor focalized transitive and ditransitive sentences. In the last 60 years, this approach towards the basic word order has been used on more than 1300 languages (Dryer and Haspelmath 2013) of various typological groups. And it is from typological point of view that the research on word 
(= sign) order in sign languages is much appreciated. Sign languages help us understand which factors that influence the basic word order in a language are modality-specific and which are universal.

\subsection{Sign languages}

Sign languages are natural human languages emerging within Deaf linguistic communities. Signers use their hands, arms, torso, face, and head in order to produce signs that are perceived visually. According to Napoli and Sutton-Spence (2014), the investigation on sign order has been carried out on 42 sign languages so far. Thanks to the increasing number of sign languages studied to date, it is now already possible to observe the main cross-linguistic tendencies in sign order. Most of the sign languages examined display SVO and SOV orders, while no sign language displaying the VSO order has ever been found. ${ }^{1}$ On the basis of this research, it is clear that sign languages generally fit in the schema of oral languages. Napoli and Sutton-Spence (2014: 1) state six generalizations that appear in the literature and seem to be connected specifically to the modality through witch sign languages are transmitted:

G1: SOV is grammatical in all sign languages.

G2: If an argument affects the phonological shape of the verb, ${ }^{2}$ it precedes the verb.

G3: The most common sentence type has only one new argument, which precedes the verb.

G4: When two arguments occur in a locational expression that forms a single clause, the larger and more immobile objects tend to precede smaller more mobile ones, regardless of their thematic role or grammatical function.

G5: Object is immediately adjacent to the verb.

G6: In reversible sentences with non-agreeing verbs, SVO is favoured.

It does not come as a surprise that visual modality plays an important role in sign order, especially since sentential structural relations in sign languages are often established through linguistic use of space. For this reason, I distinguish between different predicate types in this study and consider the most important factors that might trigger the reordering of constituents in a sentence.

\footnotetext{
${ }^{1}$ Minoura (2008) reports of the VSO and VOS orders in Malagasy Sign Language but explains them as a sporadic influence of spoken Malagasy.

${ }^{2}$ In the case of classifier predicates, for example.
} 


\subsection{This study}

In this paper, I analyse SZJ sign order according to the verb/predicate type. In section 2, I describe the methodology, namely Picture Description Task: the participants, procedure, and materials. I report the results in section 3. In section 3.1, I examine the effect of a verb class on sign order. I take into consideration transitive constructions with agreeing (3.1.1) and non-agreeing (3.1.2) verbs. In section 3.2, I examine semantic factors that concern the animacy of the arguments. Semantic features of the arguments are reported to have an impact on a wide variety of linguistic phenomena: case-assignment, choice of passive/active voice, prominence and, finally, reversibility of core arguments. I verify whether semantic factors influence sign order in SZJ. Next, I move to the environment that seems to be governed by modality-specific factors. In section 3.3, I analyse transitive non-classifier and classifier predicates (3.3.1) and ditransitive non-classifier and classifier predicates (3.3.2). I discuss the implications of these findings against the previous studies in subsection 3.3.3. Finally, in conclusion, I revisit the generalisations G1, G2, G5 and G6 (put forth by Napoli and Sutton-Spence 2014). I am not able to evaluate the generalization G3 (which considers the number of new arguments included in the sentence) because my dataset only consists of sentences that start a discourse and thus all the arguments represent new information. Neither do I discuss locative predicates (generalization G4) since this environment is rather specific in sign languages and thus requires to be addressed on its own.

\section{Methodology}

\subsection{Informants}

Signers of SZJ master their language on different levels, which is primarily due to different ways of acquiring/learning SZJ. Only a small part of the population of deaf children is raised in an SZJ speaking domestic environment that enables them to acquire SZJ as their first language (L1) without delay. Some of them are deaf and some of them are hearing bilingual children of deaf adults. Therefore, there are three groups of L1 SZJ users: a group of native deaf signers, a group of bilingual children of deaf adults, and a group of delayed deaf L1 signers. In addition, there are three more groups of SZJ signers who learn SZJ as a second language (L2): SZJ signers that learned to sign after their adolescence, foreign deaf people living in Slovenia and hearing learners of SZJ (usually either relatives of deaf people, social workers or teachers).

In this study, 6 deaf L1 signers were included ( 3 male and 3 female, all of them young adults aged from 25 to 35). They are all members of local Deaf 
clubs and are well integrated into the Deaf community. They attended school (namely Institution for the Deaf and Hard of Hearing in Ljubljana) in times when the use of SZJ was not banned any more and the so-called 'total communication' (see Lowenbraun et al. 1980) was promoted. Two of these signers are siblings. All six informants collaborated voluntarily and were not paid for their participation.

\subsection{Procedure}

As a predominant elicitation technique for this study, a standardized experimental procedure Picture Description Task, PDT, was selected. This approach enables the researcher to control the signers' production restraining them form using utterances with marked information structure, questions, and negated sentences. It was developed by Volterra et al. (1984) precisely for sign order research in sign languages and is nowadays widely used in acquisition studies as well. In the original PDT experiment by Volterra et al. (1984), the informant was given a set of pairs of pictures. In any given pair of pictures, the depicted situation differed in one aspect (for example, in one picture a boy was closing the door and in the paired picture he was opening it). One of the pictures in each pair was marked by a cross. The addressee (another native signer) was also given the very same set of pairs but with no markings on them. The informant was asked to describe the marked picture in each pair so that the addressee could identify it.

In this study, however, the informants were shown the pictures one by one and were asked to describe them to the interpreter or the deaf co-signer. This PDT experiment therefore differed from Volterra et al's (1984) original version in two ways. First, instead of paired sets single pictures were used to prevent the informants form comparing the two pictures in the set (the comparison might result in focalized structures). Second, to the addressee no pictures were given for the two signers to converse as naturally as possible and without looking at the stimuli.

In addition to the PDT, two other methods were used: Repetition Task (RT; informants repeating grammatical and ungrammatical utterances) and Grammaticality Judgement Task (GJT; informants discussing grammatical and ungrammatical utterances of a language). By these two techniques, the sentences that were produced in PDT part of the study were double-checked. It has been found that all the produced utterances were judged grammatical by all the six informants and that all the six informants were able to re-produce each other's utterances exactly as they were originally signed. Furthermore, the obtained grammaticality judgements of the (basic) sign order in researched syntactic environments did not differ across informants. PDT, RT and GJT were all conducted exclusively in SZJ. 


\subsection{Materials}

For the PDT, video clips, comics, photos, and illustrations were used as stimuli. To be able to manipulate the stimuli according to my intentions, I designed illustrations, filmed the clips and took the photos myself. I crossed 4 factors, namely: (i) verb class (agreeing / non-agreeing verbs), (ii) semantic features of the verbal arguments (reversible / irreversible arguments), (iii) predicate type (classifier / non-classifier predicates), and (iv) verbal valency (transitive / ditransitive sentences). The first set comprised 60 stimuli. In addition to the first set of stimuli, I had similar situations depicted in another set of 60 stimuli and I kept showing the stimuli until the informant produced at least 60 target responses and at least 10 structures per condition (10 transitive sentences with non-classifier agreeing verb, 10 transitive sentences with non-classifier non-agreeing verb, 10 transitive sentences with classifier predicate, 10 ditransitive sentences with non-classifier agreeing verb (namely the verb GIVE) ${ }^{3}$ and 10 ditransitive sentences with classifier predicate (namely GIVE-CL). Each of the 6 informants produced approximately 120 utterances (the total number of utterances was 725). A produced utterance did not qualify as a target response if it comprised more than one sentence or if all the arguments were not expressed overtly. After the exclusion of approximately one third of non-target utterances, the final dataset amounted to 470 sentences that were transcribed and analysed in this study.

\section{SZJ sign order}

In this section I present the results of the Picture Description Task (PDT), supported and verified by the Repetition Task (RT) and the Grammaticality Judgements Task (GJT). Sentential structures and their orders are presented with respect to the verb class (3.1), reversibility (3.2), and predicate type (3.3).

\subsection{Verb class}

In sign languages there exist two verbal categories with respect to their movement subcomponent. One class of transitive and ditransitive verbs is characterized by a path movement from one location in space (starting point, for example 'a') to another location in space (ending point, for example ' $b$ '); these verbs are conventionally glossed as ${ }_{\mathrm{a}} \mathrm{VERB}_{\mathrm{b}}{ }^{4}$ These two locations are not given

\footnotetext{
${ }^{3}$ There are no ditransitive non-agreeing verbs in SZJ.

${ }^{4}$ In this work, I adopt a common notational convention in the sign language literature according to which manual signs are glossed by a literal translation printed in English UPPER CASE (in the examples as well as in the text). Indexes are used to refer to signing locations.
} 
in the lexicon. Instead, the verb establishes them only in the sentence by copying the location values from its arguments. Because the properties of these verbs (starting and ending point) converge with the properties of their arguments and because the form of these verbs is changed according to their arguments, these verbs are considered overtly-agreeing verbs (usually only referred to as agreeing verbs). In addition to the starting and ending point of the movement, the hand orientation may also mark the verb-argument agreement: when articulating the verb sign, the hand faces the argument that is realised in the ending point of its movement. The second class of transitive verbs is deprived of path movement and/or hand orientation so that they cannot adjust their form to the location of their arguments. Consequently, there is no overt verb-argument manual agreement expressed on these verbs; they are referred to as non-agreeing or plain verbs. The two classes were first described by Padden (1983) for American Sign Language and soon extended to most sign languages studied to date. ${ }^{5}$

Let us now look at some examples. In Brazilian Sign Language examples provided by de Quadros (1999), for instance, both non-agreeing verb LIKE in (1a) and agreeing verb HELP in (2a) take two arguments, JOHN and MARY, which are assigned their locations in signing space. LIKE is not affected by these locations, while HELP is: the movement of the agreeing verb HELP starts in location of JOHN and is directed towards location of MARY. Note, that the hand is also orientated accordingly (towards MARY). In this example, JOHN qualifies as a Subject while MARY qualifies as an Object.

(1) a. JOHN LIKE MARY

b. ${ }^{*} \mathrm{JOHN}_{\mathrm{a}}$ MARY $_{\mathrm{b}}$ LIKE. 'John likes Mary'.

(2) a. JOHN ${ }_{a} \operatorname{HELP}_{\mathrm{b}} \mathrm{MARY}_{\mathrm{b}}$.

b. JOHN MARY $_{b} \operatorname{HELP}_{b}$.

Brazilian Sign Language (Quadros 2003: 149) 'John helps Mary'.

To a gloss that refers to a referent signed in location 'a', a subscribed letter is attached (like this $\operatorname{NOUN}_{\mathrm{a}}$ ). To a gloss that refers to an agreeing predicate that connects two referential locations ' $a$ ' and ' $b$ ', two subscribed letters are attached (like this ${ }_{\mathrm{a}} \mathrm{VERB}_{\mathrm{b}}$ ). Some abbreviations used: nss = neutral signing space, $\mathrm{S}=$ subject, $\mathrm{O}_{\mathrm{i}}=$ indirect object, $\mathrm{O}_{\mathrm{d}}=$ direct object, $\mathrm{IX}=$ index sign, $\mathrm{CL}$ (handshape $)=$ classifier, $\mathrm{R} 1=$ dominant hand, $\mathrm{R} 2=$ non-dominant hand, $\mathrm{PDT}=$ picture description task, GJT = grammaticality judgements task, $\mathrm{RT}=$ repetition task, $\mathrm{SZJ}=$ Slovenian Sign Language.

${ }^{5}$ See Massone and Curiel (2004) for Argentinian Sign Language, Johnston et al. (2007) for Australian Sign Language, de Quadros (1999) for Brazilian Sign Language, Sutton-Spence and Woll (1998) for British Sign Language, Quer and Frigola (2006) for Catalan Sign Language, Rathmann (2000) for German Sign Language, Sapountzaki (2005) for Greek Sign Language, Zeshan (2000) for Indopakistani Sign Language, Meir (1998) for Israeli Sign Language, Fischer (1996) for Japanese Sign Language, Hong (2008) for Korean Sign Language, Bos (1994) for Sign Language of the Netherlands and Smith (1990) for Taiwanese Sign Language. 
In many sign languages, the verb class (non-agreeing/agreeing) was shown to have an influence on sign order. In certain SVO sign languages, for example, non-agreeing verbs can only be used in strictly SVO sentences, while agreeing verbs may be found in non-basic orders, too. ${ }^{6}$ In Brazilian Sign Language, for example, both non-agreeing verbs (such as LIKE) and agreeing verbs (such as HELP) display the SVO order (Quadros 2003) as shown in (1a) and (2a), respectively. However, only agreeing verbs (2b) also support the non-basic SOV sign order while non-agreeing do not (1b). Keeping these patterns in mind, I now turn to SZJ agreeing and non-agreeing verbs in transitive sentences. A subset of stimuli in the PDT task was designed to detect the potential verbclass effect that might influence SZJ sign order.

\subsubsection{Agreeing verbs in transitive constructions}

In this subsection, I analyse selected examples of agreeing verbs in SZJ and examine the sign order of the transitive sentences that they project. VISIT in examples (3a) and ( $3 b$ ) is a one-handed sign articulated with a flat hand with all fingers extended but not spread. ${ }^{7}$ In example (3a), the signer modulates verbal movement so that it starts in location in which the argument NEIGHBOUR has previously been signed, and it ends in location in which the argument CHILD is to be signed. In example (3b), the signer modulates verbal movement so that it starts in location in which the argument CHILD has previously been signed, and it ends in location in which the argument SLOVENIA is to be articulated. The sign order of both examples (3a) and $(3 b)$ is SVO.

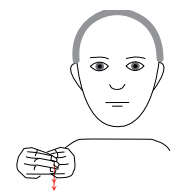

(3) a.

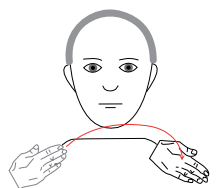

VISIT $_{\mathrm{b}}$

'A/the neighbour visits a/the child.'

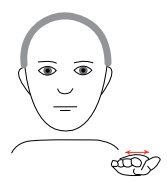

CHILD $_{b}$

${ }^{6}$ This is the case of American Sign Language (Liddell 1980; Padden 1983), German Sign Language (Rathmann 2000), Flemish Sign Language (Vermeerbergen et al. 2007), Brazilian Sign Language (Quadros 2003), Croatian Sign Language (Milković et al. 2007) and Russian Sign Language (Kimmelman 2012).

${ }^{7}$ The pictograms included in this paper are all mine (MP). They were created using SignDraw LaTeX package that was developed by Sašo Živanović within the project 'Handy video grammar of Slovenian Sign Language' (this project was carried out by Deaf and hard-of-hearing clubs association of Slovenia and co-financed by the Republic of Slovenia and the European Union under the European Social Fund). 

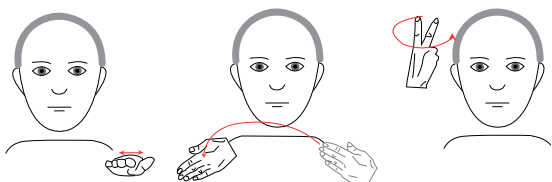

b. CHILD $_{\mathrm{b}}$

${ }_{b}$ VISIT $_{a}$

SLOVENIA

'A/the child visits Slovenia.'

Because neither sentence (3a) nor sentence (3b) requires or triggers any linguistic or non-linguistic context, I conclude that SVO is the basic sign order in SZJ. Note, that in examples (3a) and (3b) the verbal form is adjusted to the features of the verbal arguments, so that the verb agrees with its arguments. The sentential functions of the arguments are thus revealed through both the sign order and the movement of the verb. I therefore assume that their sign order could be changed (due to topicalization, for example) without affecting the decoding of the sentence. Indeed, when specifically asked to change the sign order of (3a) and (3b) in GJT, the informants produced topicalised sentences (4a) and (4b) with non-basic OSV sign order. The topicalised constituent, CHILD in (4a) and SLOVENIA in (4b), is moved to the left periphery of the sentence. In addition, it is accompanied by a brow-raise and followed by prosodic break (marked by an eye-blink and a pause, the latter is depicted as a vertical line in examples) before the rest of the sentence is signed with neutral facial expression. Detailed analysis of topicalised sign order and the process of topicalization is beyond the scope of this paper but see Kimmelman (2019) for a crosslinguistic perspective on this topic.
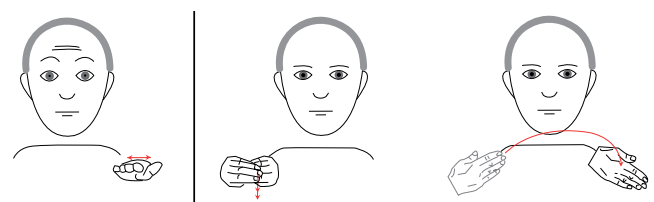

(4) a. CHILD $_{b} \quad$ NEIGHBOUR ${ }_{a}$ VISIT $_{b}$ 'It is a/the child that a/the neighbour visits.'

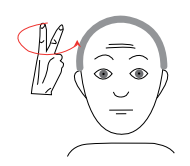

b. $\frac{\text { brow-raise }}{\text { SLOVENIA }}$

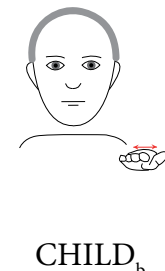

'It is Slovenia that $\mathrm{a} /$ the child visits.

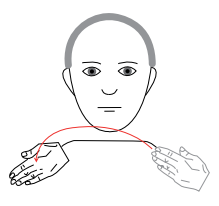

VISIT SZJ 


\subsubsection{Non-agreeing verbs in transitive constructions} (and agreement auxiliary)

In this subsection, I analyse selected examples of non-agreeing verbs in SZJ and examine the order of the transitive sentences that they project. LIKE in examples (5a) and (5b) is a one-handed sign articulated by the flat dominant hand (all fingers extended but not spread) with repeated short movements on the signer's chest. It does not qualify as agreeing verb since its dominant hand obligatorily carries out the movement touching the chest: it cannot be signed in any other location nor can it change its orientation. Therefore, LIKE is a non-agreeing verb in SZJ. As shown by examples (5a) and (5b), the obligatory sign order of transitive sentence with a non-agreeing verb is SVO. This conclusion was further verified in GJT. Without adding signs to the utterance, the informants could provide no other sign order for the sentences (5a) and (5b).
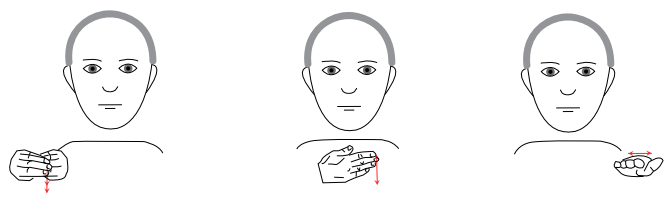

(5) a

NEIGHBOUR LIKE CHILD $_{b}$ SZJ 'A/the neighbour likes a/the child.'

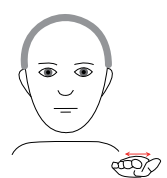

b. CHILD 'A/the child likes Slovenia.'

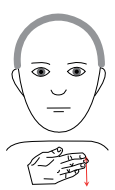

LIKE

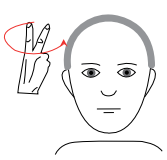

Slovenia a

In SZJ sentence with a non-agreeing verb, the non-basic sign order can only be used if additional functional sign is included in the sentence. This sign is used to overcome the lack of overt verb-argument agreement in constructions with non-agreeing verbs. Since it has all the verbal characteristics (the movement subcomponent connecting two distinct locations in signing space) except for the lexical meaning (it is deprived of lexical meaning and has to accompany a full verb), it is often analysed as an agreement auxiliary. It differs from spoken language auxiliaries because it is not used for marking tense, aspect, modality, or voice (Steele 1981); rather, its basic function is to mark verbargument agreement by modifying verbal movement (and, in certain sign languages, hand orientation). It is often glossed as AUX ('auxiliary'), but also as PAM ('Person Agreement Marker'). According to Steinbach and Pfau (2007), 
sign languages that make use of a similar auxiliary element include German Sign Language, Catalan Sign Language, Argentine Sign Language and Greek Sign Language, while American Sign Language, Hong Kong Sign Language and British Sign Language are examples of sign languages that do not use such an element.

Consider the two examples in (6). Remember that, in Brazilian Sign Language, LIKE is a non-agreeing verb (Quadros and Lillo-Martin 2010). To indicate the relations that the verb establishes with its arguments, a strict order of signs is employed (6a). If constituents are reordered due to certain linguistic processes, the information about the grammatical functions of the arguments must be conveyed in some other way. To identify the Subject and the Object in such a sentence, an auxiliary verb (glossed AUX) is introduced (6b-c). It consists of a handshape that moves from the location associated to the Subject towards the location associated to the Object. This way, JOÃO becomes the Subject while MARY becomes the Object, irrespective of their surface positions $(6 b-c)$.

(6) a. IX JOÃO LIKE IX

(Quadros and Lillo-Martin 2010: 14; LSB)

b. IX JOÃO IX ${ }_{b}$ MARY $_{a}$ AUX $_{b}$ LIKE.

c. IX $_{b}$ MARY IX JOÃO ${ }_{a} A_{a} X_{b}$ LIKE. 'John likes Mary'.

Returning to SZJ, agreement auxiliary (glossed as 'PAM') is represented in this language by a one-handed sign articulated with an extended index finger. It connects two locations in space by an arc movement and includes an orientation flip. In (7a), it is signed after the non-agreeing verb LIKE that cannot express agreement overtly. PAM starts in the location associated with CHILD (Subject) and ends in the location associated with NEIGHBOUR (Object), marking agreement overtly. When PAM is present, the sign order may be changed from basic SVO (7a) to non-basic OSV-PAM (7b) in the process of topicalization.
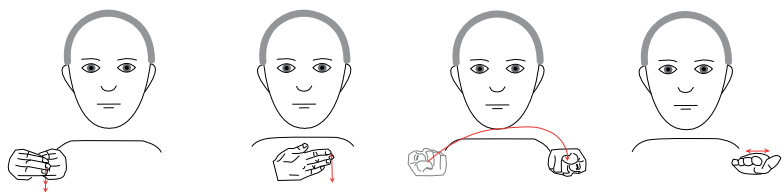

(7) a. NEIGHBOUR

LIKE 'A/the neighbour likes a/the child.'

PAM $_{b} \quad$ CHILD $_{b}$ 


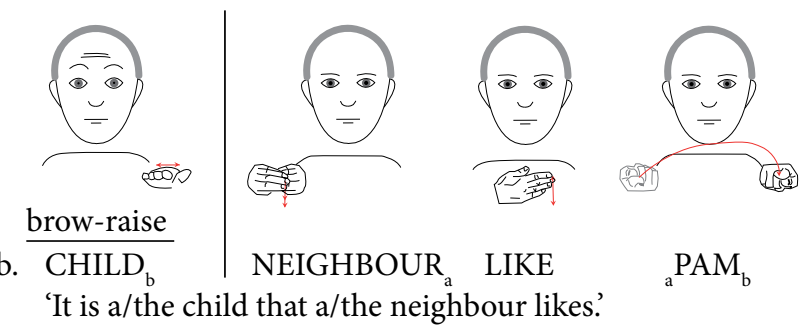

Note that according to my informants, PAM is incompatible with (i) inanimate participants as in example (8a), and (ii) agreeing verbs, such as VISIT in example (8b).
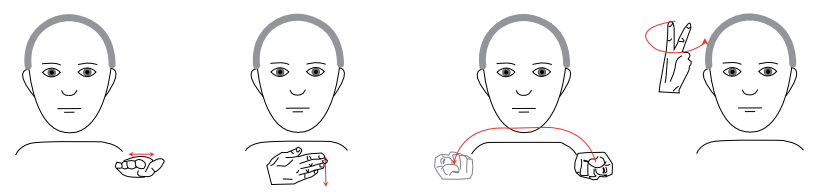

(8) a.
${ }^{*} \mathrm{CHILD}_{\mathrm{b}}$
LIKE
${ }_{b} \mathrm{PAM}_{\mathrm{a}}$
'A/the child likes a/the Slovenia.' (intended)

SLOVENIA $_{a}$

SZJ
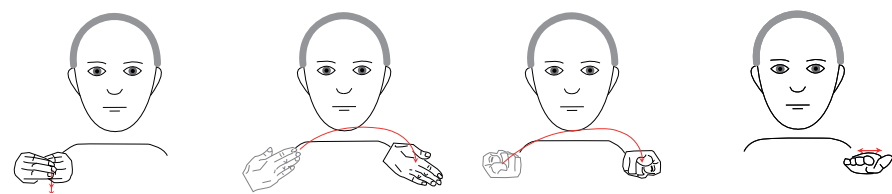

b. ${ }^{*}$ NEIGHBOUR

VISIT $_{b}$

PAM $_{\mathrm{b}}$

'A/the neighbour visits a/the child.' (intended)

CHILD $_{\mathrm{b}}$

SZJ

In this section, I showed that both non-agreeing and agreeing non-classifier verbs display the basic SVO transitive order. I conclude that, in SZJ, the verb class (agreeing/not-agreeing) does not influence the basic sign order while it does restrict the reordering that is triggered by information-structure processes such as topicalization.

\subsection{Reversibility}

In this section, I manipulate the semantic features on the arguments to examine the potential influence of the reversibility on sign order in SZJ. The reversibility of verbal arguments is conditioned by their animacy and their humaneness feature. In reversible transitive sentences, there are no semantic restrictions with respect to which thematic role may be assigned to which core verbal argument (internal or external): the verb opens two argument positions with the same set of semantic features required, and arguments that refer to participants in the event share the same set of semantic features. On the other hand, 
in non-reversible events only one of the participants qualifies as the Subject. For some sign languages, it has been shown that reversible sentences favour the SVO order - while the SOV order is used more often in non-reversible sentences. Such observations have been made for American Sign Language (Fischer 1975), Flemish Sign Language (Vermeerbergen et al. 2007) and Brazilian Sign Language (Quadros 2003). In some sign languages, like Spanish sign language (Morales-López et al. 2011), the SOV order is used with animate Subjects and inanimate Objects, while the SVO order is used with reversible Subject and Object with topicalization of an Object only being possible in case of the animate Object (Massone and Curiel 2004). In Croatian Sign Language (Milković et al. 2007), Sign language of the Netherlands (Coerts 1994), and Italian Sign Language (Volterra et al. 1984), animate arguments often precede inanimate arguments. In Russian Sign Language (Kimmelman 2012), animate Objects occur more often in the SVO order, while the inanimate Objects are more likely to appear in the SOV order. Janis (1995) further argues that in American Sign Language, animacy interacts in specific ways with thematic roles. Inanimate arguments agree with the verb when they receive roles more typically associated with animate referents: the roles of Agent, Experiencer and Recipient. However, the role of Patient can be assigned to either animate or inanimate arguments although only animate ones will agree overtly. McDonnell (1996) argues that a similar pattern holds true for Israeli Sign Language, adding that several otherwise agreeing verbs can occur without any agreement markers if their arguments are inanimate. Finally note that, on the other hand, reversibility of verbal arguments does not influence the basic order in Australian Sign Language and Irish Sign Language (Johnston et al. 2007). Focusing on reversibility in SZJ, a subset of stimuli in the PDT task was designed to detect the potential reversibility effect that might influence sign order in this language.

In example (9), both arguments are +animate (CHILD and NEIGHBOUR), therefore, each of them may take the Subject position. Since there are no semantic and morphosyntactic cues available, the information about the grammatical functions of the verbal arguments can only be determined through the basic order of sentential constituents. Indeed, with respect to the information which constituent is the Subject, the sentences in (9a) and (9b) mean exactly the opposite.
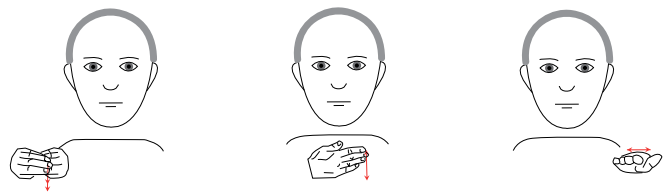

(9) a. NEIGHBOUR

LIKE

CHILD $_{\mathrm{b}}$ 


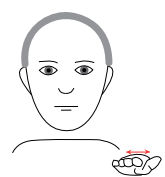

b. CHILD $_{\mathrm{b}}$

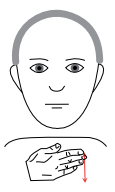

LIKE

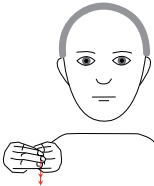

NEIGHBOUR

The sign order is the only cue to determine the argument structure in (9) and, consequently, only the basic SVO order is available here. This was confirmed in GJT, in which the six SZJ informants judged non-basic order of the topicalised sentence (10a) as degraded. On the other hand, in (10b), the verb LIKE licenses two non-reversible arguments (such as CHILD and SPAGHETTI). Therefore, in addition to the sign order, there is a semantic cue available for decoding thematic and grammatical roles of the arguments. Or to put it the other way around: since there is a semantic cue available, the basic order is not necessary, and the order of the constituents might be used to mark some other linguistic information. Consequently, topicalization may target the Object and the sentence is reordered to OSV (10b).
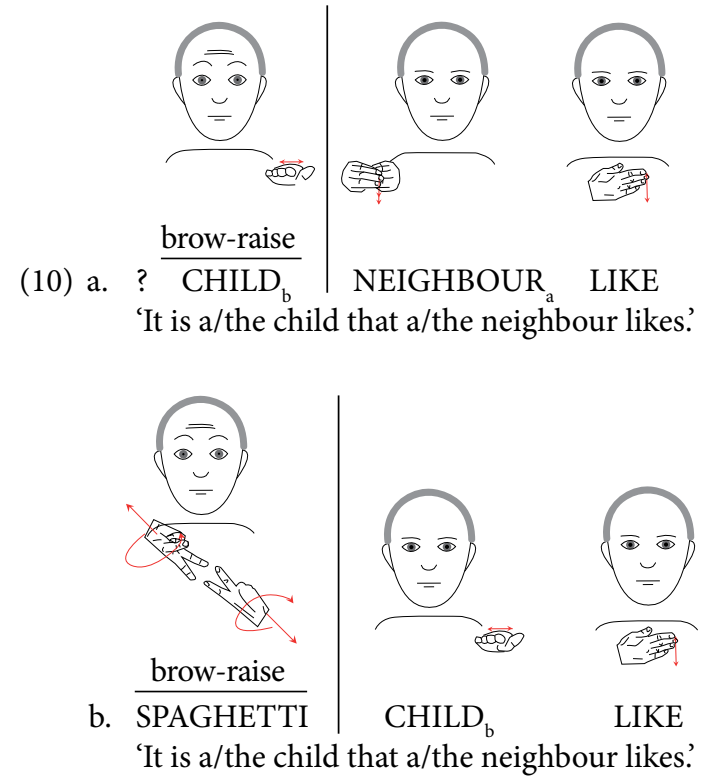

In this section, I looked for reversibility effect on sign order in SZJ and showed that, in the neutral context, there is none. My informants used the same order (SVO) in both reversible and non-reversible sentences. However, when specifically asked in GJT whether any other order is possible in these sentences, they judged topicalised non-reversible sentence (10b) as acceptable but topicalised 
reversible sentence (10a) as degraded. I conclude that only non-reversible sentences may undergo sign order change in the process of topicalization.

\subsection{Classifier and non-classifier predicates}

Classifiers in sign languages are meaningful handshapes that sort referents according to their salient characteristics. They are combined with certain verbs that lack handshape in order to form classifier predicates (verbal movement subcomponent represents their root, while the classifier handshape is a bound morpheme that refers to the participant(s) in the described event). The starting and ending point in a classifier predicate may vary according to the locations of the verbal arguments to mark verb-argument agreement (Lillo-Martin and Klima 1990).

Note that in certain sign languages with the basic SVO sign order, such as Russian Sign Language (Kimmelman 2012), Flemish Sign language (Vermeerbergen et al. 2007) and Hong Kong Sign Language (Sze 2003), classifier predicates yield an SOV sign order, as claimed for American Sign Language (another SVO language) already by Liddell (1980). Observe the examples in (11). To encode the event of cutting in Hong Kong Sign Language, either a non-classifier or a classifier predicate may be used. In (11a), a non-classifier citation form of a predicate CUT is chosen, and the sentence displays the basic sign order, which is SVO. In (11b), a non-dominant hand (R2) is added, incorporating the classifier that denotes the type of entity that is being cut (namely a loaf of bread). The predicate is now a classifier predicate (CUT-CL(loaf)) and the sentence displays the non-basic SOV order.

(11) a. MAN CUT BREAD.

(Sze 2003: 171; HKSL)

'A man is cutting some bread.'

b. WOMAN BREAD $\begin{aligned} & \text { R1: CUT } \\ & \text { R2: CL(LOAF) }\end{aligned}$

(Sze 2003: 172; HKSL)

'A woman is cutting a loaf of bread.'

Keeping the above presented patterns in mind, I will now compare the order of SZJ transitive constructions with non-classifier and classifier predicates (subsection 3.3.1), as well as the order of SZJ ditransitive non-classifier and classifier predicates (subsection 3.3.2). I discuss the findings in subsection 3.3.3.

\subsubsection{Non-classifier and classifier predicates in transitive constructions}

In this section, I determine the basic sign order of SZJ transitive sentences with respect to the type of the predicate. In a transitive minimal pair, presented in (12), I compare two variants of an SZJ sign that denotes drinking. Both variants iconically represent a liquid container directed towards the signer's mouth. In (12a), the predicate is a citation form of a non-classifier verb, 
because its handshape is stable (it can be used to denote a container of any shape, size, and type). The second one is a classifier predicate in which the handshape also refers to the container that is used for drinking but this time the handshape changes according to container's shape, size or type (in example (12b) it can only be used to denote a glass). The order in the first sentence (12a) in this minimal pair is the basic SVO, while the order of the second sentence $(12 b)$ is the non-basic SOV.

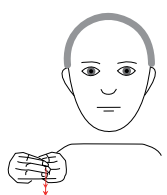

(12) a. NEIGHBOUR
'A/the neighbour drinks milk'
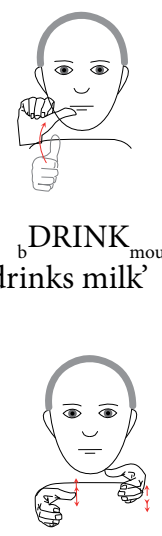

b. NEIGHBOUR MILK $_{\mathrm{b}}{ }_{\mathrm{b}}$ DRINK-CL( 圈) mouth

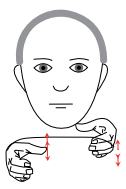

MILK $_{\mathrm{b}}$

SZJ

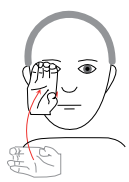

'A/the neighbour drinks milk from a/the glass.'

Since I found the non-basic SOV order in SZJ transitive classifier constructions, I expect that ditransitive classifier constructions also feature a non-basic order. Even more so, because a similar pattern was already observed in an SVO sign language, namely in Hong Kong Sign Language, as described below in 3.3.2. Note that the effect of a classifier predicate on the sign order in transitive sentences is a well-known phenomenon in sign languages while, to my knowledge, Sze (2003) is the only author noticing it in ditransitive sentences.

\subsubsection{Non-classifier and classifier predicates in ditransitive constructions}

In this section, I determine the basic sign order of SZJ ditransitive sentences with respect to the type of the predicate. Note that ditransitive constructions are under-investigated in sign languages. Sze (2003) is the only author that investigates sign order in ditransitives deliberately and in more depth. First, she examines transitive verbs and finds that the basic order in Hong Kong Sign Language is SVO whereas transitive classifier constructions feature the non-basic SOV order. Then she goes on to report $\mathrm{SVO}_{\mathrm{i}} \mathrm{O}_{\mathrm{d}}$ order (13a) in Hong Kong Sign Language non-classifier ditransitives. Sze stresses that in non-classifier ditransitives the reverse relative order of the objects $\left(\mathrm{O}_{\mathrm{d}}>\mathrm{O}_{\mathrm{i}}\right)$ is not acceptable 
(13b). She also compares the order in ditransitives with non-classifier predicates (14a) to the order in ditransitives with classifier predicates. She finds that, similar to the transitive pattern, in ditransitive sentences with classifier predicates the non-basic $\mathrm{SO}_{\mathrm{d}} \mathrm{VO}_{\mathrm{i}}$ order is attested (14b).

(13) a. FATHER BORROW MOTHER MONEY.

(Sze 2003: 182; HKSL)

b. ${ }^{\star}$ FATHER BORROW MONEY MOTHER

'Father borrows some money from mother'

(14) a. FATHER GIVE MOTHER GIFT.

(Sze 2003: 183-184; HKSL)

b. FATHER GIFT GIVE-CL(THICK-OBJECT) MOTHER.

'Father gives a gift to mother.'

I continue by looking at ditransitive structures in SZJ. Observe the minimal pair in (15) in which I compare two variants of the SZJ sign that denotes giving. In both examples they encode a ditransitive event: NEIGHBOUR gives BALL to CHILD. The sentence in (15a) is projected by a non-classifier predicate GIVE, while the sentence in (15b) is projected by a classifier predicate GIVE-CL(sphere). In both, the Subject precedes all the other constituents in the clause and, crucially, the relative order of the Direct and Indirect Object is the same: $\mathrm{O}_{d}>\mathrm{O}_{\mathrm{i}}$. The only difference between (15a) and (15b) is the type and the position of the predicate. In the sentence with a non-classifier predicate (15a) the order is $\mathrm{SVO}_{d} \mathrm{O}_{i}$, while in the sentence with a classifier predicate (15b) the order is $\mathrm{SO}_{\mathrm{d}} \mathrm{V}-\mathrm{clO}_{\mathrm{i}}$.
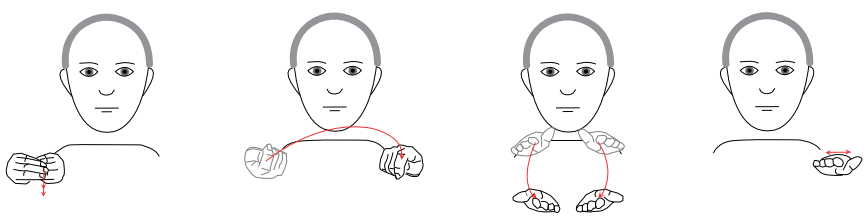

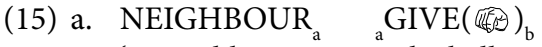
'A/neighbour gives a/the ball to a/the child.'

BALL $\quad$ CHILD $_{b}$

SZJ
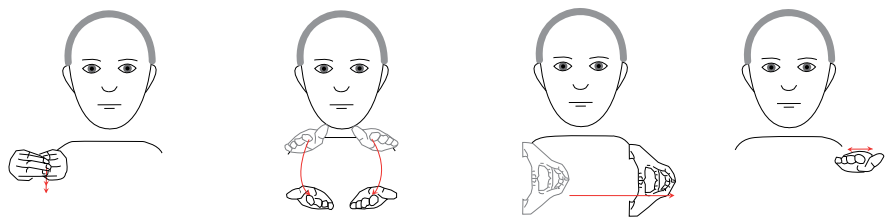

b. NEIGHBOUR

BALL

GIVE-CL( ( ह)

$\mathrm{CHILD}_{\mathrm{b}}$ 'A/the neighbour gives a/the ball of this size to a/the child.' 


\subsubsection{Deriving the non-basic sign order of classifier predicates}

In section 3.3, I manipulated the type of the predicate (non-classifier/classifier) to examine the potential influence of the iconicity on sign order in SZJ. Classifier predicates appear to be complex predicates since they are formed by classifier handshape combined with a verbal root. And precisely their complexity is assumed to trigger the non-basic SOV order in transitive sentences, since heavy constituents tend to linearize as the rightmost constituents in the sentence. However, data from SZJ and Hong Kong Sign Language ditransitive classifier constructions show that such reasoning is not on the right track simply because in these two languages ditransitive classifier predicates do not linearize as the rightmost constituents. If a classifier predicate moved to the right because of its heaviness, it would have moved to the rightmost position in both transitive and ditransitive constructions. In SZJ and Hong Kong Sign Language ditransitive classifier constructions such movement is not attested: the Indirect Object follows (and does not precede) the classifier predicate. I conclude that the explanation in terms of heavy predicate shift cannot be maintained for these two languages.

The preverbal position of the direct object in both SZJ and Hong Kong Sign Language classifier constructions could be explained by arguing that it is the Direct Object itself that moves. The problem with such explanation is finding a reason for this movement in classifier constructions. Due to the lack of evidence I discard this line of reasoning and move on to the third proposal. I assume that classifier predicates in SZJ transitive (12b) and ditransitive (15b) classifier constructions fail to move in an overt V-to-T raising, which is otherwise necessary for non-classifier transitive (12a) and ditransitive (15a) predicates. Classifier predicates simply do not undergo any reordering process. Rather, they remain in situ in their base-generated position. For SVO languages such as SZJ, this analysis correctly predicts the change from the basic SVO to the non-basic SOV for transitive classifier predicates (compare (12a) and (12b)) and from the basic $\mathrm{SVO}_{\mathrm{d}} \mathrm{O}_{\mathrm{i}}$ to the non-basic $\mathrm{SO}_{\mathrm{d}} \mathrm{VO}_{\mathrm{i}}$ (compare (15a) and (15b)) for ditransitive classifier predicates. The Hong Kong Sign Language situation is not that straightforward since the surface relative order of the objects does not match with the base-generated relative order of the objects and this is a peculiarity that Sze (2003) does not comment on. To account for HKSL data, I assume that the non-classifier predicate of the ditransitive construction pied-pipes its complement (namely the Indirect Object) when fronted in $\mathrm{V}$-to-T movement - which yields the $\mathrm{SVO}_{\mathrm{i}} \mathrm{O}_{\mathrm{d}}$ order (see example (13a)). When the ditransitive predicate is represented by a classifier predicate in this language, the V-to-T movement does not occur - which yields the $\mathrm{SO}_{\mathrm{d}} \mathrm{VO}_{\mathrm{i}}$ order (see example (14b)). In the future, such tentative analysis needs to be further explored and evaluated by (i) examining further examples of complex predicates in sign languages (such as verbs inflected for Aspect), and (ii) explaining 
why the classifier predicate fails to undergo V-to-T movement in SZJ (and possibly in other sign languages).

\section{Conclusion}

Sign order reveals the identity of a language and is needed as a point of reference for any further research. In this paper, I analysed SZJ transitive and ditransitive constructions with respect to their basic sign order pattern. To determine the basic sign order, I investigated the cross-linguistic factors that are reported to trigger changes in word/sign order. Besides the reversibility factor, I focused on the different types of predicates (agreeing/non-agreeing verbs and classifier/non-classifier predicates) and argument structure (transitive and ditransitive predicates). Below, I revisit the generalisations enlisted by Napoli and Sutton-Spence (2014) and evaluate them considering my results.

G1: Although SZJ is an SVO language (see examples 3, 5, 9, and 12a), SOV order is indeed grammatical under certain conditions in this language (namely in constructions with classifier predicates - see example 12b). By this, G1 is confirmed in SZJ.

G2: The Object argument of a classifier predicate indeed affects its phonological shape; consequently, in surface structure the Object precedes the predicate (see examples $12 \mathrm{~b}$ and $15 \mathrm{~b}$ ). By this, G2 is confirmed in SZJ.

G3: Not investigated because it refers to sentences in spontaneous production ("The most common sentence type has only one new argument, which precedes the verb”) while I investigated complete sentences with no covert arguments that were produced in isolation.

G4: Not investigated because the complexity and specificity of the locative constructions in sign languages require a comprehensive study on its own.

G5: While in my dataset each "Object is [indeed] immediately adjacent to the Verb" in the basic order, I cannot entirely confirm G5 since there exists at least one syntactic environment, namely transitive sentences with topicalised Object that allows for non-basic and non-adjacent configurations of the Object with respect to the Verb (OSV) - see examples (4), (7b), and (10).

G6: I cannot entirely confirm or reject G6 which states that in reversible sentences with non-agreeing verbs, SVO is favoured. In SZJ, reversibility does not play a role in investigated neutral-context sentences where SVO is used (see example 9) except under certain independent conditions (classifier predicates), in which SOV is attested (see example 12b). However, in transitive sentences with non-agreeing verbs and without an 
auxiliary, topicalization is better judged if the Object is inanimate and the sentence is irreversible (compare 10a and 10b).

To conclude, SZJ was found to exhibit many sign order tendencies that were reported for human languages in general and for sign languages in particular. It was shown that like oral languages, SZJ appears to be a language with a basic word/sign order, namely SVO, but that there also exist certain factors that tend to trigger the non-basic SOV order in this language.

\section{Acknowledgements}

This study was partially supported by the Scholarship for Slovenian citizens for postgraduate study abroad number 11010-716/2012, COST Action IS1006 summer school grant IS1006-060614-044777, Ca' Foscari internal funds for $\mathrm{PhD}$ mobility and Slovenian association of deaf clubs (Zveza Društev Gluhih in Naglušnih Slovenije). For their generous collaboration, I am greatly indebted to my deaf informants. I am also grateful to Chiara Branchini, to the SPL editor Ewa Willim and to anonymous reviewers. All the remaining errors are my own.

\section{References}

Bos Helen (1994). An auxiliary verb in Sign Language of the Netherlands. In Perspectives on Sign Language Structure, Inger Ahlgren, Brita Bergman, Mary Brennan (eds.), 37-53. Durham: ISLA.

Coerts Jane (1994). Constituent order in Sign Language of the Netherlands and the functions of orientations. In Ahlgren, Bergman, Brennan (eds.), 69-88.

Dryer Matthew S., Haspelmath Martin (eds.) (2013). The World Atlas of Language Structures Online. Leipzig: Max Planck Institute for Evolutionary Anthropology. http://wals.info.

Emmorey Karen (ed.) (2003). Perspectives on Classifier Constructions in Sign Languages. Mahwah, NJ: Lawrence Erlbaum and Associates.

FisCHER Susan D. (1975). Influences on word order change in ASL. In Word Order and Word Order Change, Charles N. LI (ed.), 1-25. Austin, TX: University of Texas Press.

Fischer Susan D. (1996). The role of agreement and auxiliaries in sign language. Lingua 98, 103-120.

GREENBERG Joseph H. (1963). Some universals of grammar with particular reference to the order of meaningful elements. In Universals of Language, Joseph H. GREEnBERG (ed.), 73-113. London: MIT Press.

Hawkins John A. (1983). Word Order Universals. Michigan: Academic Press.

Hong Sung-Eun (2008). Eine Empirische Untersuchung zu Kongruenzverben in der Koreanischen Gebärdensprache. Hamburg: Signum. 
JANIS Wynne D. (1995). A crosslinguistic perspective on ASL verb agreement. In Karen Emmorey, Judy S. Reilly (eds.), Language, Gesture, and Space, 195-223. New York: Hillsdale.

Johnston Trevor, Vermeerbergen Myriam, Schembri Adam, Leeson Lorraine (2007). Real data are messy: Considering cross-linguistic analysis of constituent ordering in Auslan, VGT, and ISL. In Visible Variation: Comparative Studies on Sign Language Structure, Pamela M. Perniss, Roland Pfau, Markus Steinbach (eds.), 163-205. Berlin: Mouton de Gruyter.

Kimmelman Vadim (2012). Word order in Russian Sign Language: An extended report. Linguistics in Amsterdam 5(1), 1-55.

Kimmelman Vadim (2019). Information Structure in Sign Languages. Berlin: De Gruyter Mouton Sign (series: Language and Deaf Community).

Liddell Scott K. (1980). American Sign Language Syntax. Hague: Mouton Publishers.

Lillo-Martin Diane, Klima Edward S. (1990). Pointing out differences: ASL pronouns in syntactic theory. In Theoretical Issues in Sign Language Research, Susan D. Fischer, Patricia Siple (eds.), 191-210. Chicago: University of Chicago Press.

Lowenbraun Judy Lee, Appelman Sheila, Callahan Karen I. (1980). Teaching the Hearing Impaired through Total Communication. Columbus, OH: Charles E. Merrill. Massone María, Curiel Mónica (2004). Sign order in Argentine Sign Language. Sign Language Studies 5(4), 63-93.

McDonnell Patrick (1996). Verb categories in Irish Sign Language. Dublin: Centre for Language and Communication Studies (CLCS), University of Dublin. PhD dissertation.

MeIr Irit (1998). Syntactic-semantic interaction in Israeli Sign Language verbs: The case of backwards verbs. Sign Language and Linguistics 1, 1-33.

Milković Marina, Bradarić-Jončić Sandra, Wilbur Ronnie B. (2007). Information status and word order in Croatian SL. Clinical Linguistics and Phonetics 21(11-12), 1007-1017.

Minoura Nobukatsu (2008). Word order in Malagasy Sign Language. Area and Culture Studies 77, 74-96.

Morales-López Esperanza, Reigosa-Varela César, Bobillo-García Nancy (2011). Word order and informative functions (topic and focus) in Spanish Signed Language (LSE) utterances. Journal of Pragmatics 44(4), 474-489.

NAPoli Donna Jo, SutTon-Spence Rachel (2014). Order of the major constituents in sign languages: Implications for all language. Frontiers of Psychology 5, 1-18.

PADDEN Carol (1983). Interaction of morphology and syntax in American Sign Language. San Diego: University of California.PhD dissertation.

PICHLER Deborah Chen (2001). Word order variation and acquisition in American Sign Language. Storrs, CT: University of Connecticut. PhD dissertation.

QuAdros Ronice Müller de (1999). Phrase structure of Brazilian Sign Language. Porto Alegre: Pontificia Universidad Católica do Rio Grande do Sul. PhD dissertation.

QuAdros Ronice Müller de (2003). Phrase structure of Brazilian Sign Language. In Cross-linguistic Perspectives in Sign Language Research: Selected Papers from TISLR 2000, Anne BAKer, Crasborn van Den Bogaerde (eds.), 141-163. Hamburg: Signum.

Quadros Ronice Müller de, Lillo-Martin Dianne (2010). Clause structure. In Dianne Brentari (ed.), Sign Languages: A Cambridge Language Survey, 225-252. Cambridge: Cambridge University Press. 
Quer Josep, Frigola Santiago (2006). Cross-linguistic research and particular grammars: A case study on auxiliary predicates in Catalan Sign Language (LSC). Paper presented at Workshop on Cross-linguistic Sign Language Research, Nijmegen.

Rathmann Christian (2000). The Optionality of Agreement Phrase: Evidence from Signed Languages. Austin: University of Austin. MA thesis.

Sapountzaki Galini (2005). Free Functional Markers of Tense, Aspect, Modality and Agreement as Possible Auxiliaries in Greek Sign Language. Bristol: Centre of Deaf Studies, University of Bristol. PhD dissertation.

Sмiтн Wayne (1990). Evidence for Auxiliaries in Taiwan Sign Language. In Theoretical Issues in Sign Language Research, Susan D. Fischer, Patricia Siple (eds.), 211-228. Chicago: Chicago University Press.

Steele Susan (1981). An Encyclopedia of AUX: A Study in Cross-Linguistic Equivalence. Cambridge, MA: MIT Press.

Steinbach Marcus, Pfau Roland (2007). Grammaticalization of auxiliaries in sign languages. In Perniss, Pfau, Steinbach (eds.), 303-339.

SugISAKI Koji (2003). Innate constraints on language variation: Evidence from Child Language. Storrs, CT: University of Connecticut. PhD dissertation.

SugISAKI Koji (2005). Early acquisition of basic word order: New evidence from Japanese. In Proceedings of the $29^{\text {th }}$ Annual Boston University Conference on Language Development, Alejna Brugos, Manuella R. Clark-Cotton, Seungwan Ha (eds.), 582-591. Somerville, MA: Cascadilla Press.

SugISAKI Koji (2008). Early acquisition of basic word order in Japanese. Language Acquisition 15, 183-191.

Sutton-Spence Rachel, Woll Bernice (1998). The Linguistics of British Sign Language. Cambridge: Cambridge University Press.

Sze Felix Y. B. (2003). Word order of Hong Kong Sign Language. In Bogaerde, Crasborn, Mills-BAKer (eds.), 163-192.

Vermeerbergen Myriam, Herreweghe Mieke van, Akach Philemon, Matabane Emily (2007). Constituent order in Flemish Sign Language (VTG) and South African Sign Language (SASL): A crosslinguistic study. Sign Language and Linguistics 10(1), 25-54.

Volterra Virginia, Laudanna Alessandro, Corazza Serena, Radutzky Elena, Natale Francesco (1984). Italian Sign Language: the order of elements in the declarative sentence. In Recent Research on European Sign Languages, Penny Boyes-Braem, Filip Loncke, Yvan Lebrun (eds.),19-48. Lisse: Swets \& Zeitlinger.

ZeShan Ulrike (2000). Sign Language in Indo-Pakistan. A Description of a Signed Language. Philadelphia/Amsterdam: John Benjamins Publishing Company.

Matic Pavlič

Faculty of Education, University of Ljubljana

Kardeljeva ploščad 16

1000 Ljubljana, Slovenia

matic.pavlic(at)pef.uni-lj.si 